\title{
História da Educação Física das escolas públicas do município de Icó-CE: inserção e prática docente
}

\author{
The history of Physical Education in public schools in Icó-CE (Brazil): insertion and teaching \\ practice
}
Historia de la Educación Física de las escuelas públicas en Icó-CE (Brasil): inserción y práctica docente

\author{
Paulo Rogério de Lima ${ }^{\mathrm{I}}$, Sílvia Maria Nóbrega-Therrien ${ }^{\mathrm{II}}$
}

\begin{abstract}
Resumo
Este estudo objetivou constituir a história da Educação Física da Escola de $1^{\circ}$ Grau Vivina Monteiro e do Grupo Escolar Professora Lourdes Costa, localizados no município de Icó-CE (Brasil), destacando a inserção e a prática docente nos primeiros anos de implantação. Para isso, desenvolvemos uma pesquisa de abordagem qualitativa de caráter histórico, tendo a História Oral como técnica. Assim, este estudo contou com o entrelaçamento da história oral de dois professores aposentados que lecionaram em ambas as escolas, e da análise de documentos. $\mathrm{Na}$ instituição de ensino Vivina Monteiro, a Educação Física foi inserida em 1976, e na Professora Lourdes Costa, em 1982. Nessas escolas, a prática docente da Educação Física pautava-se em atividades para melhoria dos níveis de aptidão física e o desempenho de habilidades motoras e esportivas. Essas constatações contribuem para a compreensão histórica da Educação Física nas escolas cearenses, permitindo reflexões críticas sobre a prática dos professores ao longo do tempo.
\end{abstract}

Palavras-chave: Educação Física; Prática docente; Escolas; História

\begin{abstract}
This study aimed to constitute the history of Physical Education of Vivina Monteiro 1st Grade School and Professora Lourdes Costa School Group, located in the city of Icó-CE (Brazil), highlighting insertion and teaching practice in the first years of implementation. For this, we developed a research of qualitative approach of historical character, using Oral History as a technique. Thus, this study included the intertwining the oral history of two retired teachers who taught at both schools, and the analysis of documents. At Vivina Monteiro institution, Physical Education was introduced in 1976, and at Professor Lourdes Costa School, in 1982. In these schools the teaching practice of Physical Education was based in activities to improve the levels of physical aptitude and performance of motor and sports activities. These findings contribute to the historical comprehension of the Physical Education at schools in Ceará, allowing critical reflections about teachers' practice over time.
\end{abstract}

Keywords: Physical Education; Teaching practice; Schools; History

\footnotetext{
${ }^{\text {I }}$ Universidade Estadual do Ceará - UECE - Endereço: Av. Dr. Silas Munguba, 1700 - Campus do Itaperi, Fortaleza, CE CEP: 60.714.903

- e-Mail: progerio.sport@gmail.com

II Universidade Estadual do Ceará - UECE - e-mail: silnth@terra.com.br
} 


\section{Resumen}

Este estudio objetivó constituir la historia de la Educación Física de la Escuela de primero Grado Vivina Monteiro y del Grupo Escolar Profesora Lourdes Costa, ubicada en la ciudad de Icó-CE (Brasil), destacando la inserción y la práctica docente en los primeros años de implantación. Para eso, desarrollamos una pesquisa de abordaje cualitativa de carácter histórico, tiendo la Historia Oral como técnica. Así, este estudio contó con el entrelazado de la historia oral de dos profesores jubilados que impartían clases en ambas las escuelas y del análisis de documentos. En la institución de enseñanza Vivina Monteiro, la Educación Física fue inserida en 1976, y en la Profesora Lourdes Costa en 1982. En esas escuelas, la práctica docente de la Educación Física estaba basada en actividades para la mejoría de los niveles de aptitud física y el desempeño de habilidades motoras y deportivas. Estos hallazgos contribuyen a la comprensión histórica de la Educación Física en las escuelas de Ceará, permitiendo reflexiones críticas sobre la práctica de los docentes a lo largo del tiempo.

Palabras clave: Educación Física; Práctica docente; Escuelas; Historia

\section{Introdução}

É comum, no campo historiográfico da Educação Física, quando não possuímos registros locais, nos reportarmos às informações históricas derivadas de pesquisas realizadas em outras regiões brasileiras. Diante dessa situação, Rocha (2011, p.23) nos alerta que “[...] olhar a história da Educação Física por apenas um ângulo é perder de vista os estudos das diferentes realidades sociais que compõem o conjunto do país [...]". Assim, para a referida autora, não é interessante negligenciarmos as especificidades locais e continuarmos generalizando estudos elaborados em outras realidades do país.

Sendo mais incisiva na defesa de realização de investigações sobre a história da Educação Física local, Rocha (2011, p.23) menciona que “o Ceará, embora ligado ao contexto maior, possui particularidades que podem e devem ser estudadas, analisadas, comparadas e produzir novos conhecimentos, pesquisas e debates". Nesse ensejo, direcionamos nossa atenção para os fenômenos históricos do município interiorano cearense, denominado de Icó, onde estamos inseridos profissionalmente desde 2015.

O município de Icó está situado na microrregião do Centro-Sul cearense, a uma distância aproximada de $375 \mathrm{~km}$ da capital do Estado, Fortaleza. É uma localidade que possui grande representatividade histórica para o Ceará, por ter sido a terceira vila a ser instalada em seu território, precisamente no ano de 1738, logo após Aquiraz e Fortaleza. Além disso, se destacou na produção agrícola e na pecuária, configurando-se numa rota comercial estratégica do Nordeste. A referida cidade foi projetada pela Corte Imperial, sendo que seus casarões, igrejas e teatro são acervos do patrimônio nacional tombados pelo Instituto do Patrimônio Histórico e Artístico Nacional (IPHAN), desde o ano de 1998. 
Apesar de toda a historicidade que permeia o referido município, notamos a falta de registros históricos sobre os processos educacionais, sobretudo no que se refere à Educação Física escolar. Diante desse contexto, nos questionamos: como a Educação Física se constituiu historicamente no currículo das escolas icoenses? Qual o ano de sua inserção na matriz curricular? E, quais eram as principais práticas desenvolvidas pelos professores de Educação Física nos primeiros anos de sua implantação nas escolas?

Mediante a essas indagações, objetivamos, neste estudo ${ }^{1}$, constituir ${ }^{2}$ a história da Educação Física da Escola de $1^{\circ}$ Grau Vivina Monteiro e do Grupo Escolar Professora Lourdes Costa, destacando a identificação do ano de inserção na matriz curricular e a evidenciação da prática docente nos primeiros anos de sua implantação.

Essas instituições de ensino foram selecionadas para desenvolvimento da pesquisa por possuírem grande representatividade na história educacional icoense, estando entre as pioneiras a ofertar a educação pública local e por serem criadas a partir da reivindicação de membros da comunidade para atender aos anseios educacionais, sobretudo da população desprovida financeiramente.

Ressaltamos que o entendimento de prática docente utilizado neste estudo, ancora-se na concepção de Franco (2016), ao concebê-la como a prática pedagógica do professor, que não se restringe apenas às técnicas de didáticas adotadas em sala de aula, mas envolve também outros aspectos, como os espaços e tempos escolares e a própria organização do trabalho docente. Nesse sentido, a terminologia prática docente é utilizada nesta pesquisa para se referir ao trabalho que foi realizado pelos professores de Educação Física nas instituições de ensino Vivina Monteiro e Professora Lourdes Costa.

Esta pesquisa torna-se relevante por contribuir para a compreensão da constituição histórica da Educação Física nas escolas cearenses, preenchendo lacunas em relação à inserção e à prática docente na história da Educação Física do município de Icó-CE. Além disso, os registros elucidados neste estudo auxiliam para a reflexão e análise crítica da prática docente de Educação Física ao longo do tempo, e ainda permite a valorização dos registros da história das especificidades e identidades culturais locais.

\section{Metodologia}

Para atingir o objetivo deste estudo foi realizada uma pesquisa de abordagem qualitativa (MINAYO, 2001) de caráter histórico (LOBIONDO-WOOD; HABER, 2001), se utilizando da História

\footnotetext{
${ }^{1}$ As informações contidas neste escrito são oriundas do resultado de uma pesquisa de abrangência maior, que buscou obter a compreensão da história da Educação Física nas escolas de Icó-CE, no período de 1946 a 1983. A referida pesquisa foi desenvolvida para a construção da dissertação de mestrado defendida em 2019, no Programa de Pós-Graduação em Educação (PPGE), da Universidade Estadual do Ceará (UECE).

${ }^{2}$ Neste estudo, "constituir" é utilizado na perspectiva de registar e/ou relatar a história da Educação Física nas referidas escolas.
} 
Oral como técnica. De acordo com Meihy e Holanda (2013, p. 70), como técnica, a História Oral supõe a existência de "uma documentação paralela, escrita ou iconográfica, e que as entrevistas entrariam como mais um apêndice formalizado, maneira precisa de diálogo de fontes". Assim, essa constituição histórica resultou do cruzamento de dados oriundos da História Oral dos sujeitos e de documentos, que nos permitiram encontrar evidências da inserção e da prática dos professores na Educação Física.

Como fontes documentais, foram utilizadas Atas de resultados finais e Diário de classe, encontradas, em sua maioria, nas secretarias das escolas pesquisadas, a partir de nossas visitas a tais ambientes, ocorridas no mês de janeiro de 2019. Utilizamos o Termo de Fiel Depositário nas duas instituições de ensino por nos fornecerem a documentação para nosso estudo.

A História Oral foi realizada com dois professores aposentados, um homem e uma mulher, que ensinaram a Educação Física em ambas as escolas pesquisadas. Para a realização da entrevista, entramos em contato com os professores participantes via telefone, para agendarmos uma data, horário e local. A entrevista com a professora aconteceu em sua residência e durou 25 minutos, já com o professor, por preferência dele, ocorreu na sala de avaliação da Escola Ana Vieira Pinheiro ${ }^{3}$ e teve duração de 30 minutos.

As entrevistas foram realizadas no início de janeiro de 2019, seguiram um roteiro de questões semiestruturado, sendo gravadas com auxílio do gravador de voz do celular e, posteriormente, salvas em uma pasta no notebook, onde fizemos a transcrição. Depois da transcrição, retornamos o contato com os participantes da pesquisa, para a validação das informações da entrevista. Ressaltamos que os dois professores foram informados previamente acerca das particularidades do estudo e dos seus objetivos e, ao optarem por participar da pesquisa, assinaram o Termo de Consentimento Livre e Esclarecido (TCLE). Apontamos também que, neste estudo ${ }^{4}$, para a preservação do anonimato, os professores participantes receberam os codinomes de João Paulo e Sandra Maia.

\section{Inserção na matriz curricular e prática docente da Educação Física nas escolas Vivina Monteiro e Professora Lourdes Costa do município de Icó-CE}

Para uma melhor compreensão sobre a história da Educação Física nessas duas instituições de ensino do município de Icó-CE, optamos neste estudo, organizar as informações separadas em subtópicos, abordando as suas respectivas peculiaridades com relação aos contextos de surgimento institucional, à

\footnotetext{
${ }^{3}$ Escola onde o referido professor também lecionou aulas de Educação Física.

${ }^{4} \mathrm{Na}$ realização da pesquisa, dispusemo-nos a garantir ao máximo, as condições éticas, observando algumas recomendações da Resolução do Conselho Nacional de Saúde (CNS) n $n^{\circ}$ 510, de 07 de abril de 2016, que "dispõe sobre as normas aplicáveis a pesquisas em Ciências Humanas e Sociais" (BRASIL, 2016).
} 
inserção na matriz curricular da Educação Física e às evidências da prática docente desse componente escolar.

3.1 História da Educação Física na Escola de $1^{\circ}$ Grau Vivina Monteiro: inserção e prática docente

A Escola Vivina Monteiro teve sua origem no ano de 1973, funcionando no Círculo Operário como instituição de ensino municipal. Em 1974, funcionou nas dependências do Centro Icoense de Ensino Técnico (CIENTE), ano em que passou a pertencer à rede estadual, tendo funcionado também de agosto de 1976 até dezembro de 1978 no Colégio Senhor do Bonfim, passando a ter sede própria em 1979, sendo denominada de Escola de $1^{\circ}$ Grau Vivina Monteiro. É interessante frisarmos que, até o final de 1975 , a escola ofertava de $1^{\mathrm{a}}$ a $4^{\mathrm{a}}$ série $^{5}$ (antigo primário), mas, em 1976, passou a oferecer de $5^{\mathrm{a}}$ a $8^{\mathrm{a}}$ série $^{6}$. A partir do referido ano, constatamos a presença da Educação Física como disciplina na matriz curricular (conforme Figura 01- marcações nossas em amarelo).

Figura 01 - Fragmento do livro de Ata de Resultados Finais da Escola de $1^{\circ}$ Grau Vivina Monteiro do ano de 1976

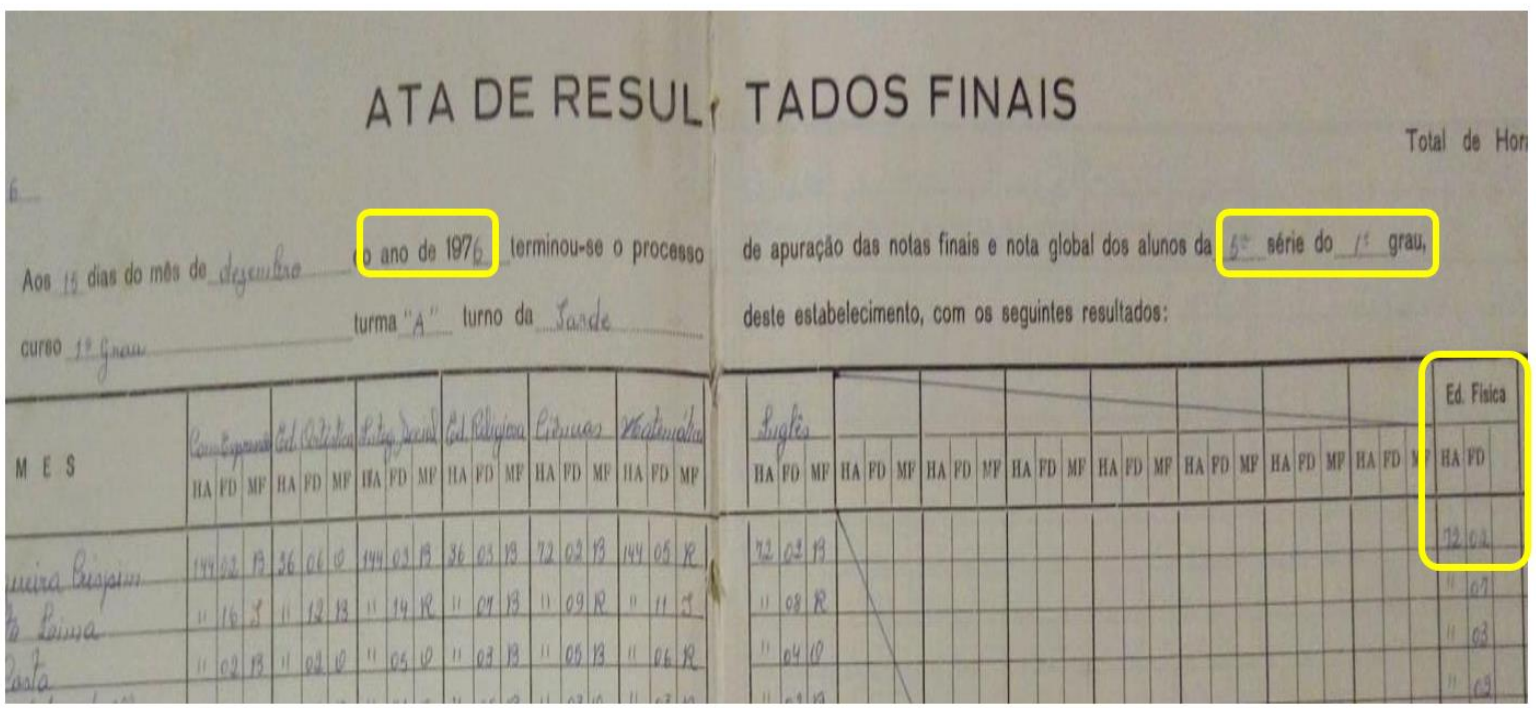

Fonte: Secretaria da Escola de Ensino Médio Vivina Monteiro ${ }^{7}$ (1976)

Analisando a ATA DE RESULTADOS FINAIS da turma da $5^{a}$ série, que funcionava à tarde, no ano de 1976, podemos constatar que as disciplinas ofertadas para essa turma eram: Comunicação e Expressão, Educação Artística, Integração Social, Educação Religiosa, Ciências, Matemática, Inglês e Educação Física. Em relação à Educação Física, percebemos que não havia notas, o registro se restringia

${ }^{5}$ Corresponde de $2^{\circ}$ a $5^{\circ}$ ano do Ensino Fundamental.

${ }^{6}$ Corresponde de $6^{\circ}$ a $9^{\circ}$ ano do Ensino Fundamental.

${ }^{7}$ Nome atual da Escola de $1^{\circ}$ Grau Vivina Monteiro. 
à carga horária e ao número de faltas. Percebemos que, nessa época, a prática da Educação Física era organizada em sessões, que se registravam, prioritariamente, a carga horária e a frequência.

É importante ressaltarmos que nesse período a Educação Física, em termos de legislação estava sob a influência do Decreto Federal nº9.450, de $1^{\circ}$ de novembro de 1971, que no seu Artigo $1^{\circ}$, concebia-a como uma atividade capaz de promover o desenvolvimento e o aprimoramento das forças físicas, morais, cívicas, psíquicas e sociais dos alunos. Para Castellani Filho (2010, p.84), a Educação Física nos currículos sob a forma de uma atividade, caracterizava-se por um fazer pelo fazer, “[...] uma mera experiência limitada em si mesma, destituída do exercício da sistematização e compreensão do conhecimento, existente apenas empiricamente".

Abreu, Sabóia e Nóbrega-Therrien (2019, p. 196) mencionam que "o processo de militarização na Educação Física brasileira sustentava o trato do conhecimento sobre o saber-fazer, arquitetado eminentemente na prática, portanto, uma fragilidade no trato do conhecimento sobre o campo teórico". Assim, percebemos que o ensino da Educação Física se restringia ao desenvolvimento de atividades práticas, caracterizadas pela reprodução de movimentos.

A prática nas aulas de Educação Física na Escola de $1^{\circ}$ Grau Vivina Monteiro acontecia no horário diferente do turno em que os alunos tinham as outras disciplinas, mas, mesmo assim, havia assiduidade dos discentes. O professor participante do estudo, João Paulo (2019), sobre essa adesão dos alunos às aulas de Educação Física, conta-nos que:

No turno da noite a gente fazia não era dentro do horário, isso era final dos anos 1970 e início dos anos 1980, a educação física era de manhã e de tarde. A turma da tarde a gente aproveitava saindo da escola, aí era de $17 \mathrm{~h}$ as $19 \mathrm{~h}$, e a turma de manhã, às vezes, vinha à tarde também, tinham uns que preferiam vim à tarde, e a turma da noite vinha pela manhã, umas 5 h, e aí era de 5 h e meia até $7 \mathrm{~h}$. Naquela época era separada, tinha o dia das mulheres e o dia dos homens. [...] A participação era de $80 \%$ porque uns trabalhavam não podiam, aí vinha com declaração do trabalho, e outro, que tinha doença arrumava um atestado médico, tinha que justificar [...].

Colaborando com o assunto, a professora participante do estudo, Sandra Maia (2019) complementa que as aulas de Educação Física na referida escola ocorriam "[...] cedinho e de tardezinha e, às vezes, nos últimos horários da noite", e acrescenta que "os alunos dos sítios (zona rural) eram dispensados porque não tinham condição de vim em outro horário".

Diante das narrativas dos professores entrevistados, notamos informações associadas à adesão e à dispensa dos alunos. Aderiam porque, entendemos, eram aulas interessantes para eles, mas constatamos um tipo de dispensa pela dificuldade de acesso, principalmente porque moravam distante da sede e, 
notadamente, da escola. Esse tipo de dispensa era próprio da escola e do município, uma vez que, oficialmente, não havia dispensas por esse motivo. Contudo, há a possibilidade de a escola considerar esses alunos como trabalhadores, visto que grande parte era filhos de agricultores e ajudava seus pais no roçado $^{8}$. Ressaltamos, ainda, que nessa prática as turmas eram formadas por sexo, tendo um dia específico para os homens e outro para as mulheres.

É relevante destacarmos que o Decreto Federal nº 69.450, de 1 de novembro de 1971, no inciso III do Artigo $5^{\circ}$, recomendava a composição de turmas com "alunos do mesmo sexo" e de preferência com "nível de aptidão física" similar. Além disso, no seu Artigo 6º alínea a, tornava a prática facultativa aos alunos trabalhadores, e na alínea d, discentes que apresentassem problemas de saúde comprovados por laudo médico que impossibilitasse a sua participação nessa disciplina (BRASIL, 1971).

Para Soares et al. (2012, p. 38), a normatização do ensino da Educação Física implementada pelo referido decreto, pautada na formação das turmas por sexo, com o mesmo nível de aptidão física e a organização de atividades em dias alternados, “[...] dão relevância a aspectos de ordem físiológica [...]”. Em relação à facultatividade para alguns alunos, Darido e Rangel (2005, p.56) ressaltam que essa decisão assegurada na legislação, abre "[...] a possibilidade de exclusão das aulas desse conteúdo a um grande número de pessoas que se beneficiariam muito se as frequentassem".

É importante ressaltarmos que, nessa época, a organização da aula de Educação Física é descrita pelo professor João Paulo (2019) da seguinte forma:

Para iniciar, eu fazia um alongamento, fazia um aquecimento, ai fazia aquela calistenia, exercícios tradicionais, e, dali, depois que o aluno estava preparado, entrava com a parte de esporte, aí, às vezes, dentro da modalidade, as meninas iam jogar vôlei, [...] formei um time de handebol feminino e outro masculino, treinava o pessoal para as corridas.

Podemos notar que, nesse período, o conteúdo principal era o esporte. Na aula existia um momento de preparação (com aquecimento, alongamento) e a parte principal era a prática de alguma modalidade esportiva. De acordo com Soares et al. (2012), a influência do esporte nas aulas de Educação Física aumentou significativamente no período pós-guerras mundiais (1945), seguindo uma tendência internacional, sob a influência, principalmente, da cultura europeia. Nessa época foi-se fortalecendo o processo de esportivização generalizada nas aulas de Educação Física nas escolas brasileiras.

Abreu, Sabóia e Nobrega-Therrien (2019, p. 198) mencionam que no período da Ditadura Militar (1964-1985), o esporte foi utilizado pela elite governante para tirar o foco da população das questões sociais e políticas, e, nesse sentido, “[...] o esporte se tornou objeto ideológico a partir do fenômeno da

${ }^{8}$ Relativo às atividades da roça, trato com o mato, cuidado com a lavoura. 
'espetacularização', cuja finalidade era silenciar e arregimentar forças oponentes aos movimentos sociais $[\ldots] "$.

Para Soares et al. (2012, p. 53), o esporte atingiu uma grande magnitude no sistema escolar dos anos de 1960 a 1980, de modo que o esporte praticado na escola era subordinado aos códigos/sentido da instituição esportiva. Destarte, era concebido “[...] como um prolongamento da instituição esportiva: esporte olímpico, sistema desportivo nacional e internacional”.

Nesse sentido, observamos que as competições esportivas dentro das escolas passam a ter grande destaque. O professor João Paulo(2019) explica-nos que as instituições de ensino do município de Icó-CE (CIENTE, Colégio Senhor do Bonfim, Grupo Escolar Ana Vieira Pinheiro, Grupo Escolar Professora Lourdes Costa e Escola de $1^{\circ}$ Grau Vivina Monteiro) realizavam os jogos interclasses com as modalidades esportivas (provas de atletismo, futebol, voleibol) praticadas nas aulas de Educação Física, depois disso, faziam a seleção da escola para participar dos jogos intercolegiais (que era a competição entre as escolas do referido município).

Ainda de acordo com o professor João Paulo (2019), nos jogos havia tanto as modalidades esportivas masculinas, quanto as femininas, só que na competição das mulheres formavam-se menos equipes, e não tinham representação em todos os esportes ofertados na competição. O referido docente complementa que as equipes se apresentavam uniformizadas e tinha premiação de troféus para os vencedores. Nas competições, as torcidas eram animadas e cada uma tinha sua forma ou música para incentivo de sua equipe.

No tocante às condições para prática da Educação Física na Escola de $1^{\circ}$ Grau Vivina Monteiro, o professor João Paulo (2019) conta-nos que:

Quando a gente ia treinar no Vivina, nesse tempo não tinha quadra, mas tinha um espaço grande interno, então dava para fazer um campinho para jogar futebol. A gente usava os recursos que tínhamos, quando eu ia treinar os meninos para corrida, eu fazia a pista de corrida de velocidade, fazia a caixa de salto tudo lá dentro, cavando na chibanca e colocando areia, fazendo as raias. Tinha um espaço amplo, mas depois fizeram muitas salas de aulas, e construíram uma quadra.

Tecendo considerações sobre esse assunto, a professora Sandra Maia (2019) ressalta que a Escola de $1^{\circ}$ Grau Vivina Monteiro não oferecia muitos materiais. Ela direcionava suas práticas muito para o atletismo, que ocorria, muitas vezes, no espaço de frente à escola. Desse modo, podemos constatar que os professores não tinham à disposição os materiais necessários, construindo seus próprios espaços de prática e desenvolvendo atividades viáveis à realidade. 
Diante do exposto, constatamos que a inserção da Educação Física na Escola de $1^{\circ}$ Grau Vivina Monteiro ocorreu a partir do ano de 1976, na matriz curricular da $5^{\text {a }}$ série. Percebemos que as aulas de Educação Física estavam fundamentadas, principalmente, pela prática de modalidades esportivas (atletismo, futebol, voleibol, handebol), sendo antecedidas de uma parte inicial de preparação com aquecimento e alongamento. Destacamos, ainda, que os docentes conviviam com dificuldades de espaços e materiais para o desenvolvimento das aulas, contudo faziam o esforço de adequar os ambientes e objetos para a prática acontecer.

3.2 História da Educação Física no Grupo Escolar Professora Lourdes Costa: inserção e prática docente

O Grupo Escolar Professora Lourdes Costa foi fundado em 17 de maio de 1967. Nos primeiros anos de funcionamento dessa instituição, era ofertado apenas o ensino primário, distribuído em três turnos. Apesar da vigência da Lei de Diretrizes e Bases n 4024, de 20 de dezembro de 1961, que em seu Artigo 22, determinava que a prática da Educação Física deveria ser obrigatória nos cursos primário e médio até a idade de 18 anos, não encontramos evidências do ensino desse componente curricular no ensino primário da referida escola.

No Grupo Escolar Professora Lourdes $\operatorname{Costa}^{9}$, só encontramos evidências oficiais do ensino da Educação Física no início da década de 1980, mais precisamente no ano de 1982, na $5^{\text {a }}$ série da turma A, do turno da manhã (conforme Figura 02 - marcações nossas em amarelo).

Figura 02 - Fragmento do livro de Ata de Resultados Finais do Grupo Escolar Professora Lourdes Costa do ano de 1982

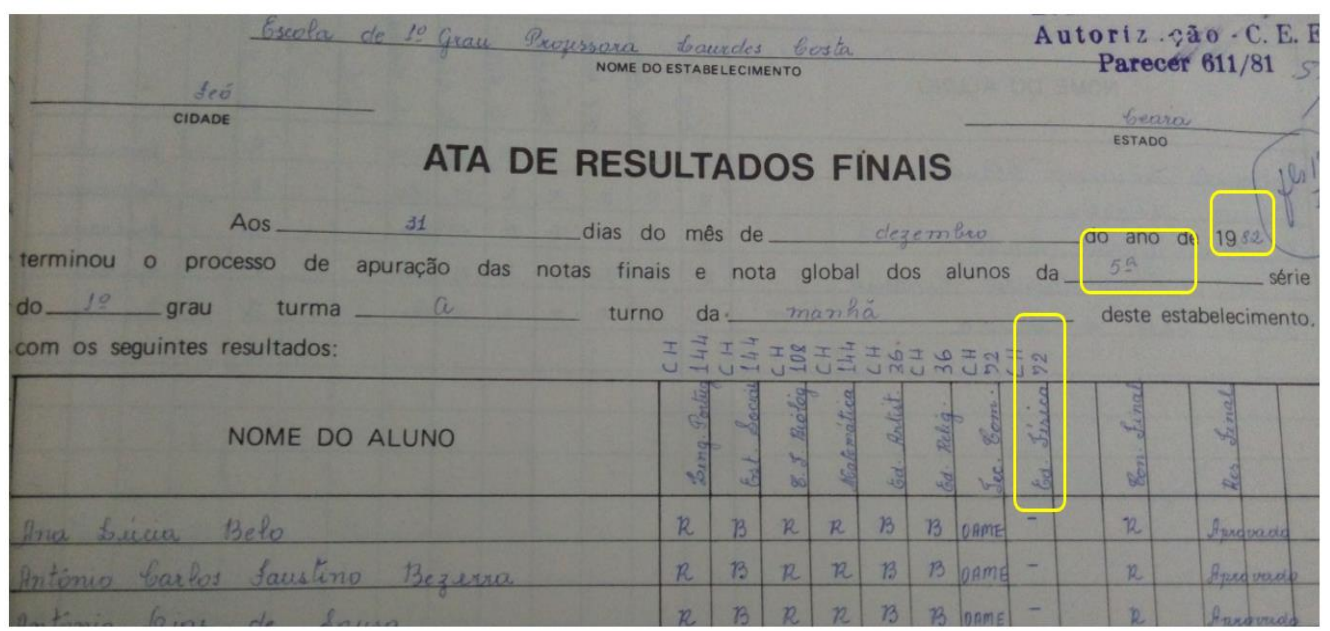

Fonte: Secretaria da Escola Municipal Professora Lourdes $\operatorname{Costa}^{10}(1982)$

9 Nessa época a referida Instituição de Ensino estava com nova nomenclatura "Escola de $1^{\circ}$ Grau Professora Lourdes Costa".

${ }^{10}$ Nome atual do Grupo Escolar Professora Lourdes Costa. 
Notamos, a partir desse fragmento, que a matriz curricular da $5^{\text {a }}$ série A era composta pelas disciplinas: Língua Portuguesa, Estudos Sociais, Ciências Físicas e Biológicas, Matemática, Educação Artística, Educação Religiosa, Técnicas Comerciais e Educação Física. Evidenciamos, ainda, que em relação às demais, a Educação Física era a única disciplina que não apresentava nota, apenas a menção à carga horária, o que reiteramos, que a aula era eminentemente prática e o registro oficial preconizava a frequência.

Observamos que nessa época existia a recomendação da realização dos exames clínicobiométricos e avaliação da aptidão física nas escolas públicas cearenses. Encontramos evidências disso em um diário de classe das turmas de $5^{\mathrm{a}}$ séries $\mathrm{A}$ e $\mathrm{B}$ e $6^{\mathrm{a}}$ série $\mathrm{A}$, da disciplina de Educação Física, do ano letivo de 1983. Percebemos que o referido diário, logo em sua contracapa, trazia as instruções para a realização dos exames clínico-biométricos, enfatizando as orientações sobre registro de datas, peso, estatura, laudo médico e observações (conforme Figura 03).

Figura 03- Instruções em relação aos exames clínico-biométricos contidas no diário de classe das $5^{\text {a }}$ e $6^{\mathrm{a}}$ séries do Grupo Escolar Professora Lourdes Costa do ano de 1983

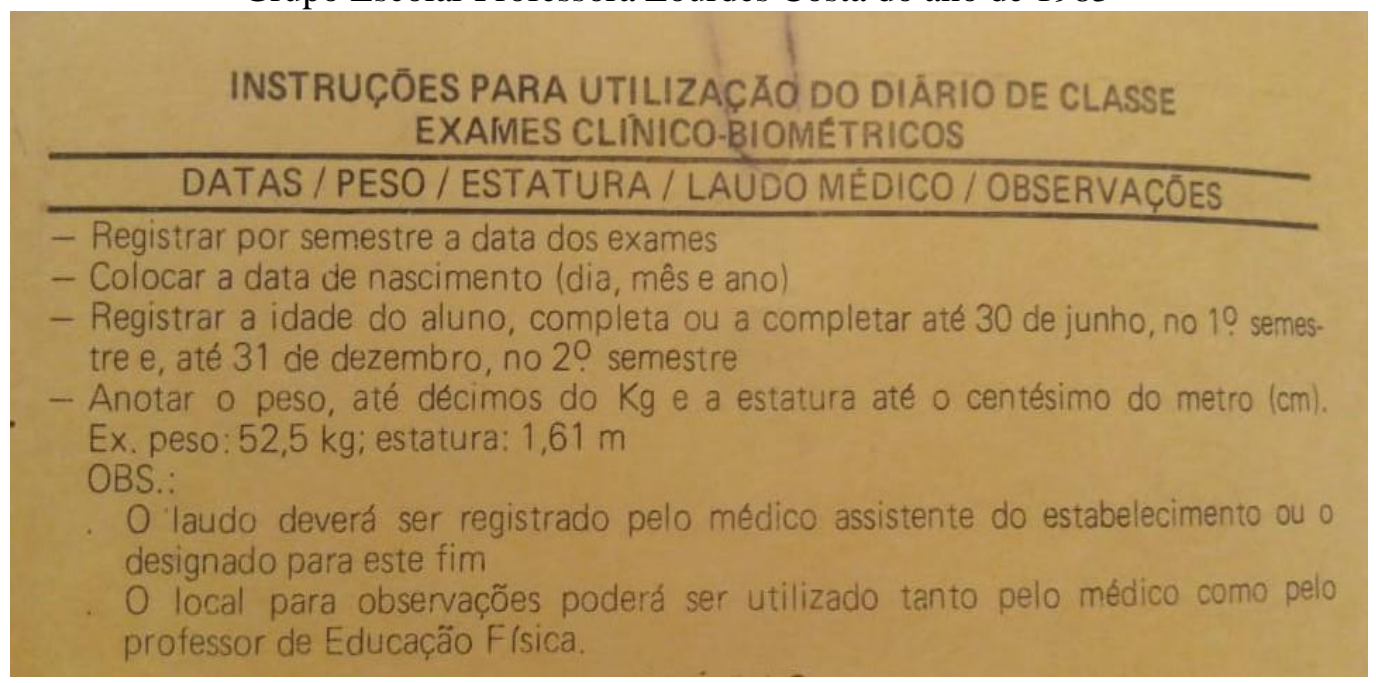

Fonte: Arquivo permanente da Escola Municipal Professora Lourdes Costa (1983)

Nessas instruções, notamos a padronização dos registros em relação à biometria dos alunos, recomendando a realização do exame duas vezes ao ano, isto é, um a cada semestre, atentando para a data e a idade discente, sendo que na anotação do peso, os décimos de kg deveriam ser considerados, assim como os centésimos do metro, quando a medida fosse a estatura. Outro detalhe é a orientação do registro do laudo por um médico. Ressaltamos que havia um espaço no próprio diário para preenchimento desses dados. 
Dito isso, mencionamos que os procedimentos para o preenchimento desses dados fizeram parte por alguns anos da prática do professor de Educação Física. O docente João Paulo (2019) nos conta como acontecia o exame clínico-biométrico na escola:

Eu fazia o exame biométrico, pesava, media. [...] inclusive, o médico tinha que ir à escola, para ver eu fazer. Tinha o exame médico também, o médico era para ir, mas não ia. Aí o que é que eu fazia, além de fazer aquele exame de pesar e medir todos, que aprendi lá no quartel, durante o exercício eu verificava os batimentos cardíacos, mesmo sem aparelhos. Aí tirava na pulsação, os batimentos cardíacos. Media direitinho no início, no meio e no final, para ver se tinha alguma alteração com o aluno. Eu fazia antes do aquecimento, depois do aquecimento, depois do exercício você já via a diferença. Se está em repouso, está ali entre 60 a 80 batimentos, depois do aquecimento variava de 80 a 100, e depois do exercício pesado, vai de 130 a 150 batimentos cardíacos. Com base nisso, se tivesse alguma alteração brusca no aluno, a gente indicava para um médico, ao invés do médico olhar todo mundo, só olhava quem tinha problema.

Percebemos que na prática, muitas vezes, o exame clínico-biométrico era realizado somente pelo professor de Educação Física. De acordo com o docente João Paulo (2019), a escola entrava em contato com o médico, que era contratado pelo Estado para atender à população do município. Esse profissional da saúde marcava o horário que estaria disponível para comparecer à escola para a realização desse exame, uma ou duas vezes ao ano. Contudo, muitas vezes não comparecia, justificando falta de tempo.

Trazendo relatos sobre esse exame clínico-biométrico, a professora Sandra Maia (2019) revela que após examinado pelo médico, "se o aluno apresentasse algum problema de coluna, de osteoporose, problemas na perna, às vezes num braço [...]”, era afastado e emitido um atestado que o dispensaria por um ano, “[...] mas não era muita gente que apresentava".

Destacando as instruções nesse diário de Educação Física das turmas de $5^{\mathrm{a}}$ séries A e B e $6^{\mathrm{a}}$ série A, em relação à avaliação, mencionamos que considerava a aptidão física, aspectos avaliativos e conteúdos (conforme Figura 04). 
Figura 04 - Instruções em relação à avaliação dos discentes contidas no diário de classe das $5^{\text {a }}$ e $6^{\text {a }}$ séries do Grupo Escolar Professora Lourdes Costa do ano de 1983

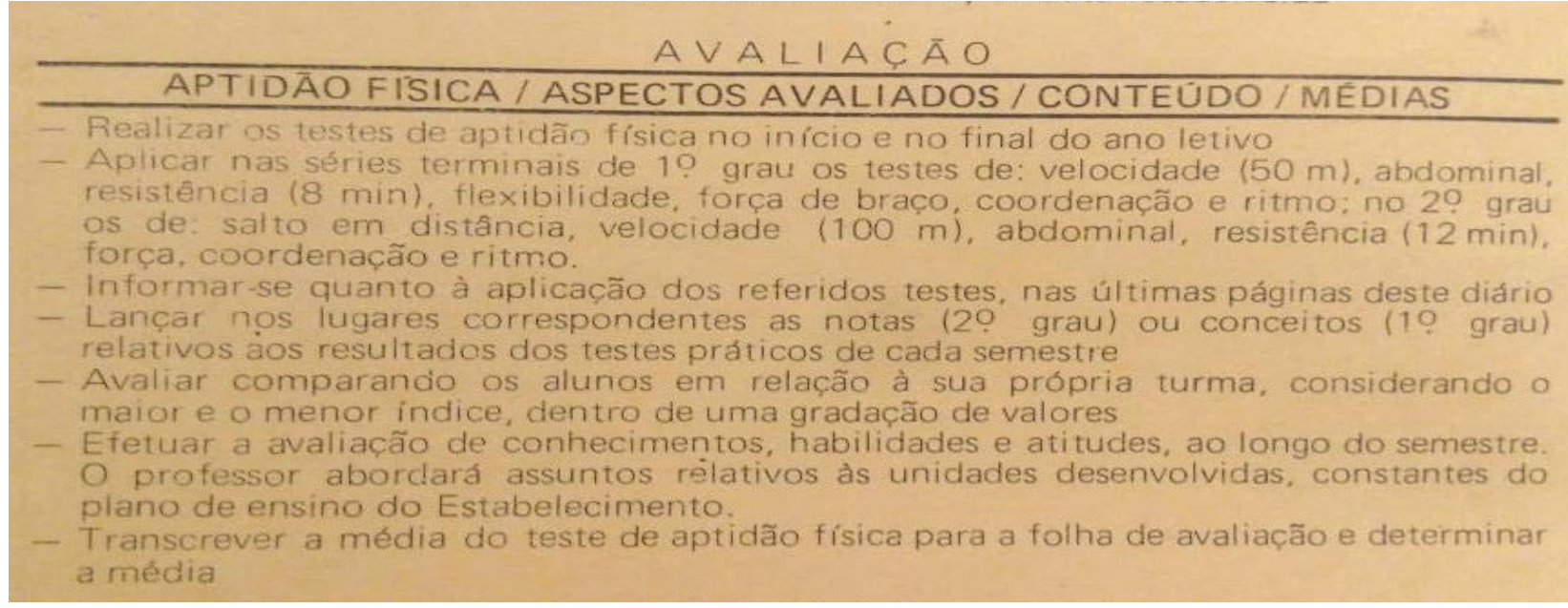

Fonte: Arquivo permanente da Escola Municipal Professora Lourdes Costa (1983)

Nessas orientações direcionadas aos professores, notamos que os testes de aptidão física deveriam ser realizados duas vezes ao ano, uma no início e outra ao final, sendo que para as séries do $1^{\circ}$ grau maior $^{11}$, era orientada a aplicação dos testes de velocidade $(50 \mathrm{~m})$, abdominal, resistência $(8 \mathrm{~min}$.), flexibilidade, força de braço, coordenação e ritmo. Já no $2^{\circ}$ grau era o salto em distância, velocidade (100 m), abdominal, resistência (12 min.), força, coordenação e ritmo. No $2^{\circ}$ grau os registros dos resultados dos testes deveriam constar em notas e no $1^{\circ}$ grau em conceito. É importante frisarmos que na parte final do diário existiam todas as orientações detalhadas de como realizar cada teste de aptidão física, constando a descrição, procedimentos de realização, indicação de local adequado, os materiais necessários e como fazer os registros.

Para Corrêa (2009), essas atividades de realização do exame biométrico e testes de aptidão física, que inicialmente era sistematizada numa ficha individual do aluno, foi uma prática estabelecida pelo ministro da Educação e Saúde, Francisco Campos, na Era Vargas (1930-1945), que recebeu influência do método de ginástica francês. De acordo com esse autor, no governo Vargas, esses dados deveriam ser encaminhados para os órgãos governamentais para trabalhos com fins estatísticos e, no caso específico dos resultados dos exames práticos, a finalidade era averiguar se o desempenho do aluno "[...] correspondia ou não o valor físico dos jovens" (CORRÊA, 2009, p. 100).

Notamos que essas práticas se prolongaram no período da Ditadura Militar (1964-1985), mantendo a intenção de classificar e selecionar os alunos, a partir do seu desempenho físico, uma maneira

${ }^{11}$ Séries do $1^{\circ}$ grau maior correspondem aos anos finais do Ensino Fundamental $\left(6^{\circ}\right.$ a $9^{\circ}$ anos $)$ e o $2^{\circ}$ grau equivale ao Ensino Médio. 
de acompanhar o crescimento e desenvolvimento da juventude para atender às expectativas de mercado e defesa da pátria.

No tocante ao exame prático, a professora Sandra Maia (2019), nos conta que "existia um tempo que era para fazer as atividades, aí tinha vários tipos de exercícios e, cada exercício, dependendo do tempo, era atribuída uma nota". A referida docente ressalta que "do mesmo jeito que o homem fazia, a mulher também fazia, só que para a mulher era menor o número de repetições e o tempo de duração dos exercícios".

O professor João Paulo (2019) nos explica que realizava "os testes de corrida, apoio de frente, abdominais e barras", só que em relação às mulheres, se a corrida para homem fosse 2.800 metros em 3 minutos, para elas o percurso era menor, por exemplo, 2.000. Lembra ainda que "mulher não fazia o apoio de frente nem tinha a barra, para elas, tinha o abdominal e polichinelo".

Ainda em relação à prática de avaliação em Educação Física, destacamos a recomendação no diário em questão, de efetuar a avaliação de conhecimentos, habilidades e atitudes do aluno ao longo dos semestres. Percebemos que além da avaliação física, deveria o professor atentar para as capacidades cognitivas e comportamentais do aluno.

Com base no diário de classe das turmas de $5^{\mathrm{a}}$ séries A e B e $6^{\mathrm{a}}$ série $\mathrm{A}$, da disciplina Educação Física da referida escola, no ano letivo de 1983, podemos constatar, a partir dos registros de aulas do $3^{\circ}$ bimestre (início do $2^{\circ}$ semestre), que algumas atividades práticas (Figura 05) envolviam o atletismo (corrida de velocidade, salto em distância) e exercícios direcionados para grupos musculares (postura) e atividades com bolas. 
Figura 05 - Registro das atividades das turmas de $5^{\mathrm{a}}$ e $6^{\mathrm{a}}$ séries da disciplina Educação Física do Grupo Escolar Professora Lourdes Costa do ano de 1983

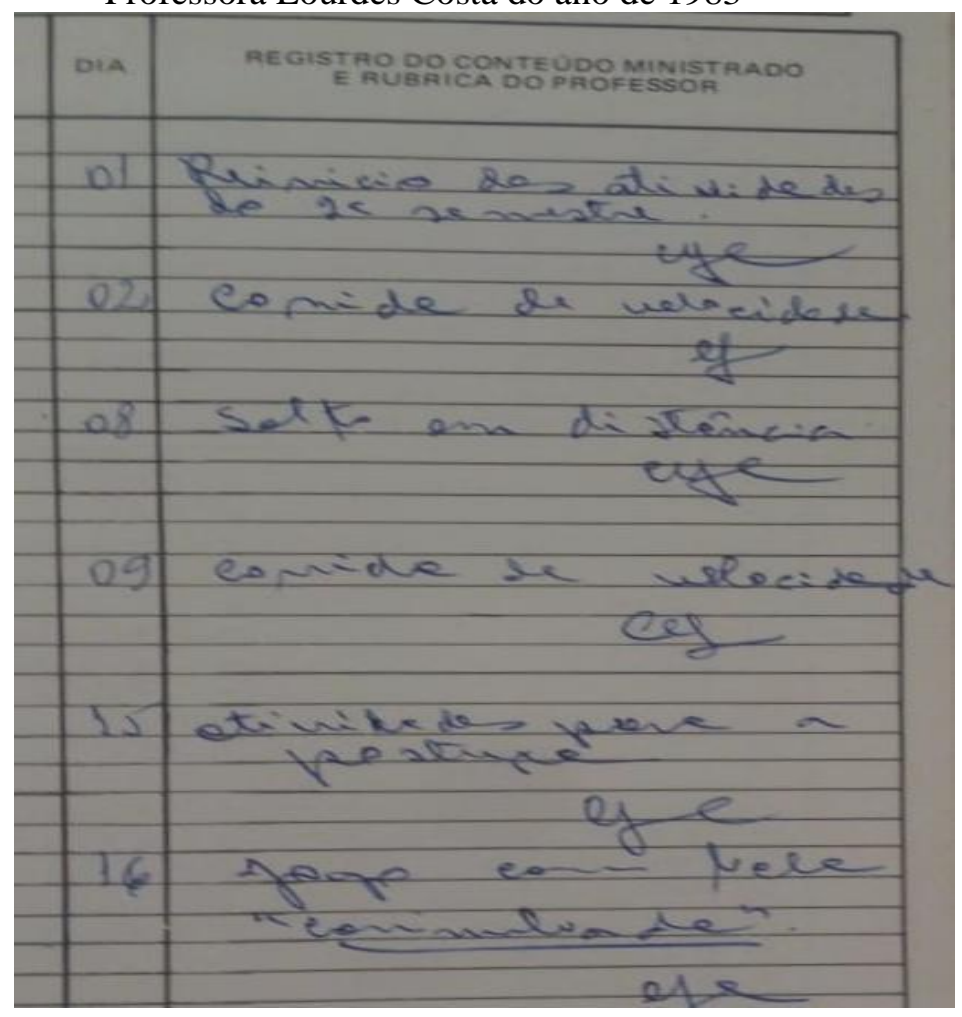

Fonte: Arquivo permanente da Escola Municipal Professora Lourdes Costa (1983)

Observando esses registros, a professora Sandra Maia (2019) lembra-nos que a prática da Educação Física era desenvolvida em um galpão que havia na escola, e que muitos dos materiais que utilizavam para a prática eram de propriedade do próprio professor. A docente enfatiza ainda, que “[...] trabalhava com muita corrida porque a corrida não precisa de material”. Para Rangel Betti (1999, p. 29), o ensino do atletismo na escola tem se limitado apenas " [...] a corrida de velocidade, de resistência e de alguns saltos[...]" tendo como justificativa dos docentes a falta de alguns materiais. Contudo, a autora complementa que isso pode ser alterado, ressaltando que o professor pode utilizar, para trabalhar com as outras provas do atletismo, "[...] barreiras confeccionadas com latas, cimento e cabos de vassoura, colchões com pneus, e pesos feitos de areia e tecido".

Diante do exposto, constatamos que a inserção da Educação Física no Grupo Escolar Professora Lourdes Costa aconteceu com a oferta de turmas de $5^{\text {a }}$ séries, a partir de 1982, sendo que as práticas desenvolvidas pelos professores pautavam-se na realização de exames clínico-biométricos e avaliação da aptidão física por meio de testes práticos orientados para acontecer semestralmente. Além disso, desenvolviam atividades com bolas. A maioria das práticas acontecia num galpão, localizado na parte interna da escola, sendo que o material utilizado para o desenvolvimento da aula era, em sua maioria, pertencente ao professor. 


\section{Considerações finais}

Estudos que se propõem à constituição histórica da Educação Física são sempre desafiadores e, ao mesmo tempo, instigantes pela busca e contato com fontes que possam nos subsidiar de dados para montarmos um enredo da história. Nessa perspectiva, este estudo contou com o entrelaçamento das informações oriundas da história oral e da análise documental. Ressaltamos que a identificação da inserção da Educação Física na Escola de $1^{\circ}$ Grau Vivina Monteiro, em 1976, e no Grupo Escolar Professora Lourdes Costa, em 1982, se deu por meio de análise de documentos institucionais (livros de atas de resultados finais) fornecidos pelas respectivas escolas.

Na Escola de $1^{\circ}$ Grau Vivina Monteiro, constatamos que a Educação Física era praticada em locais adaptados e construídos, muitas vezes, pelos próprios professores, que também conviviam com a falta de materiais para o desenvolvimento das aulas. As turmas eram divididas por sexo, as aulas aconteciam em dias distintos para homens e mulheres. Geralmente, a parte inicial da aula era preparatória, com exercícios de alongamento e aquecimento, e o momento principal era voltado para a prática de alguma modalidade específica (atletismo, futebol, voleibol).

No Grupo Escolar Professora Lourdes Costa, verificamos uma prática docente na Educação Física caracterizada pela realização semestral de exames clínico-biométricos (aferição do peso, altura, registro da idade) e avaliação da aptidão física a partir de testes práticos (velocidade, abdominal, resistência, flexibilidade, força de braço, coordenação e ritmo). Além disso, evidenciamos o registro de práticas de exercícios físicos direcionados para grupos musculares localizados (postura) e atividades com bolas, ocorrendo em sua maioria, no galpão da escola.

Diante do exposto, percebemos que nos primeiros anos de implantação em ambas as escolas, a Educação Física estava caracterizada por uma prática muito limitada em relação à formação integral humana, priorizando melhorias dos níveis de aptidão física e desempenho de habilidades motoras e esportivas, numa perspectiva de instrumentalização técnica.

Por fim, a partir das pistas apontadas nos achados e as principais constatações, esperamos que esta pesquisa possa inspirar mais pesquisadores a conhecerem e produzirem cientificamente sobre os aspectos históricos da Educação Física, de modo que promovam melhoria da compreensão histórica do conhecimento nesse componente curricular, considerando a valorização das especificidades locais.

\section{Referências}

ABREU, Samara Moura Barreto de; SABÓIA, Wilson Nóbrega; NÓBREGA-THERRIEN, Sílvia Maria. 
Formação docente em Educação Física: perspectivas de uma racionalidade pedagógica do corpo em movimento. Educação \& Formação, Fortaleza, v. 4, n. 12, p. 191-206 set./out. 2019. Disponível em: https://revistas.uece.br/index.php/redufor/article/view/897/1317. Acesso em: 05 maio 2020.

BRASIL. Conselho Nacional de Saúde. Resolução no 510, de 07 abril de 2016. Brasília, DF, 2016. Disponível em: http://conselho.saude.gov.br/resolucoes/2016/reso510.pdf. Acesso em: 18 maio 2018.

BRASIL. Decreto Federal no 69.450, de 01 de novembro de 1971. Regulamenta o artigo 22 da Lei número 4.024, de 20 de dezembro de 1961, e alínea c do artigo 40 da Lei 5.540, de 28 de novembro de 1968 e dá outras providências. Brasília, DF, 1971. Disponível em: http://www.planalto.gov.br/ccivil_03/decreto/d69450.htm. Acesso em: 10 mar. 2018.

CASTELLANI FILHO, Lino. Educação Física no Brasil: a história que não se conta. 18. ed. Campinas: Papirus, 2010.

CORRÊA, Denise A. Os governos de Getúlio Vargas (1930-1954) e a Educação Física Escolar no Estado de São Paulo: Lembranças de Velhos Professores. 2009. 230 f. Tese (Doutorado em História) Pontifícia Universidade Católica de São Paulo, São Paulo, 2009.

DARIDO, Suraya C.; RANGEL, Irene C. A. Educação Física na escola: implicações para a prática pedagógica. Rio de Janeiro: Guanabara Koogan, 2005.

ESCOLA DE $1^{\circ}$ GRAU VIVINA MONTEIRO. Ata de Resultados Finais. Icó: arquivo permanente, sala da secretaria, 1976.

FRANCO, Maria A. do R. S. Prática pedagógica e docência: um olhar a partir da epistemologia do conceito. Rev. bras. Estud. pedagog. (on-line), Brasília, v. 97, n. 247, p. 534-551, set./dez. 2016. Disponível em: http://www.scielo.br/pdf/rbeped/v97n247/2176-6681-rbeped-97-247-00534.pdf. Acesso em: 10 set. 2018.

GRUPO ESCOLAR PROFESSORA LOURDES COSTA. Ata de Resultados Finais. Icó: arquivo permanente, sala da secretaria, 1982.

GRUPO ESCOLAR PROFESSORA LOURDES COSTA. Diário de classe das turmas de $\mathbf{5}^{\mathbf{a}}$ séries A e B e $6^{\text {a }}$ série A da disciplina de Educação Física. Icó: arquivo permanente, sala da secretaria, 1983.

LOBIONDO-WOOD, Geri; HABER, Judith. Pesquisa em enfermagem: métodos, avaliação crítica e utilização. 4. ed. Rio de Janeiro: Guanabara Koogan, 2001.

MAIA, S. Entrevista concedida a Paulo Rogério de Lima por Sandra Maia. Icó, 9 jan. 2019. Duração: 25 min.

MEIHY, José C. S. B.; HOLANDA, Fabíola. História oral: como fazer, como pensar. 2. ed. São Paulo: Contexto, 2013.

MINAYO, Maria C. de S. (Org.). Pesquisa social: teoria, método e criatividade. 18. ed. Petrópolis: Vozes, 2001. $80 \mathrm{p}$. 
PAUlO, J. Entrevista concedida a Paulo Rogério de Lima por João Paulo. Icó, 10 jan. 2019. Duração: $30 \mathrm{~min}$.

RANGEL BETTI, Irene C. Esporte na escola: mas é só isso, professor? Motriz, Rio Claro, v. 1, n. 1, p. 25-31, jun. 1999. Disponível em: http://files.cursoeducacaofisica.webnode.com/20000008860238611e0/ESPORTE\%20NA\%20ESCOLA\%20-\%20IRENE\%20RANGEL.pdf. Acesso em: 10 jul. 2020.

ROCHA, Ariza M. O passado da Educação Física Escolar em Fortaleza-CE (1865-1930). Fortaleza: Edições UFC, 2011.

SOARES, Carmem L. et al. Metodologia do ensino de educação física. 2. ed. São Paulo: Cortez, 2012.

\section{Como citar este artigo}

LIMA, P. R.; NÓBREGA-THERRIEN, S. M. História da Educação Física das escolas públicas do município de Icó-CE: inserção e prática docente. Revista Kinesis, Santa Maria, v.39, p.01-17, 2021.

* O presente trabalho não contou com apoio financeiro de nenhuma natureza para sua realização. 